\title{
Pemeriksaan Logam Berat Cadmium (Cd) dan Plumbum (Pb) pada Lipstik yang Beredar di Pasar Brayan Medan Timur Secara Spektrofotometri Serapan Atom (SSA)
}

\author{
Tisna Harmawan $^{1 *}$ dan Dewi Lestari ${ }^{2}$ \\ ${ }^{1}$ Program Studi Kimia Fakultas Teknik Universitas Samudra \\ J. Meurandeh, Langsa Aceh 24416, Indonesia \\ ${ }^{2}$ Program Studi Analis Kesehatan Politeknik Kesehatan Dr Rusdi Medan \\ Jl. H Adam Malik No 138-142, Medan Sumatera Utara 20235, Indonesia \\ *Corresponding author: tisna_harmawan@unsam.ac.id
}

\begin{abstract}
ABSTRAK
Telah dilakukan penelitian Pemeriksaan Logam Berat Cadmium (Cd) dan Plumbum (Pb) Pada Lipstik Yang Beredar di Pasar Brayan Medan Timur Secara Spektrofotometri Seraparan Atom. Penelitian ini dilatar belakangi dengan adanya lipstik yang menjadi tidak aman bila tercemar logam berat yang dapat menimbulkan efek buruk terhadap kesehatan. Penelitian ini dilakukan di Unit Pelayanan Teknis Laboratorium Kesehatan Daerah Dinas Kesehatan Provinsi Sumatera Utara dengan tujuan untuk mengetahui ada tidaknya dan kadar logam berat Cadmium dan Plumbum pada lipstik yang beredar di Pasar Brayan Medan Timur. Penelitian ini bersifat eksperiment laboratorium dengan metode pengambilan sampel secara acak sebanyak 5 sampel dari seluruh populasi yang beredar di Pasar Brayan Medan Timur dengan teknik analisa data yang diperoleh dari data primer dan sekunder, disajikan dalam bentuk tabulasi yang dinarasikan dengan hasil logam berat Cadmium (Cd) dari 5 sampel diperoleh hasil analisa kualitatif dan kuantitatif dengan sebanyak dua sampel yang positif (sampel dua $=5,000 \mathrm{mg} / \mathrm{L}$ dan sampel empat $=4,950 \mathrm{mg} / \mathrm{L}$ ). sedangkan pada logam berat Plumbum $(P b)$ diperoleh empat sampel positif (sampel satu $=0,915 \mathrm{mg} / \mathrm{L}$, sampel tiga $=$ $0,295 \mathrm{mg} / \mathrm{L}$, sampel empat $=6,960 \mathrm{mg} / \mathrm{L}$ dan sampel lima $=1,515 \mathrm{mg} / \mathrm{L}$, dari hasil keseluruhan sampel yang mengandung logam berat $(C d$ dan $P b)$ diperoleh kadar dibawah standar baku ( BPOM RI Persyaratan cemaran logam Cadmium $<5 \mathrm{mg} / \mathrm{L}$ dan Plumbum $<20 \mathrm{mg} / \mathrm{L}$ atau mg/kg. Nomor HK.03.1.23.07.11.6662 tahun 2011) dengan ini perlu dilakukan pengawasan yang lebih intensif terhadap kosmetik tidak teregrestasi yang beredar di masyarakat, khususnya masyarakat Pasar Brayan Medan Timur.
\end{abstract}

Kata Kunci: Lipstik, Logam Berat Cadmium (Cd), Plumbum (Pb) dan SSA

\section{PENDAHULUAN}

Kosmetik berasal dari kata kosmetikos (Yunani) yang artinya keterampilan menghias, mengatur. Jadi kosmetik pada dasarnya adalah campuran bahan yang diaplikasikan pada anggota tubuh bagian luar seperti epidermis kulit, kuku, rambut, bibir, gigi dan sebagiannya dengan tujuan untuk menambah daya tarik, melindungi, memperbaiki, sehingga penampilannya lebih cantik dari semula. Kosmetik mulai dikenal berabad abad silam [1].

Salah satu jenis kosmetik yang digunakan adalah lipstik. Lipstik juga digunakan untuk melembabkan bibir yang dapat kering karena akibat cuaca yang kering ataupun dingin [2]. Lipstik yang digunakan harus aman dan tidak mengandung bahan yang berbahaya yang melebihi batas yang ditetapkan karena dapat ikut masuk melalui makanan dan minuman yang dikonsumsi. Pada lipstik Cadmium (Cd) dapat memberikan efek mengkilat pada bibir dan Plumbum $(\mathrm{Pb})$ pada lipstik dapat memberikan efek menempel pada bibir Menurut penelitian [3].

Lipstik dapat menjadi tidak aman bila tercemar oleh logam berat, yang dapat menimbulkan efek buruk terhadap kesehatan. Logam berat merupakan komponen alami yang terdapat di kulit bumi yang tidak dapat didegradasi ataupun di hancurkan dan merupakan zat yang berbahaya karena dapat terjadi biokumulasi [3]. Penimbunan Cadmium (Cd) terutama pada ginjal, kulit, paru dan pangkreas dan pada orang dewasa Cadmium (Cd) dapat menyebabkan kanker payudara, penyakit kardiovaskuler atau paruparu, penyakit jantung, kegagalan reproduksi bahkan dapat menyebabkan kemandulan. Plumbum $(\mathrm{Pb})$ dapat mengakibatkan gangguan sintesis darah, hipertensi, hiperaktivitas, kerusakan otak dan disfungsi ginjal. Pada wanita hamil Plumbum $(P b)$ dapat melewati plasenta dan kemudian 
akan ikut masuk dalam sistem peredaran darah janin dan selanjutnya setelah bayi lahir, Plumbum $(\mathrm{Pb})$ akan keluar bersama air susu ibu [4]. Spektrofotometri Serapan Atom (SSA) adalah salah satu alat instrument analisa yang dapat menetukan konsentrasi suatu unsur dalam suatu cuplikan yang didasarkan pada proses penyerapan radiasi sumber oleh atom-atom, yang berada tingkat energi dasar. SSA merupakan suatu metode analisa yang sangat spesifik dan sensitive untuk logam [5].

Di Indonesia telah ditemukan cemaran kadmium dan timbal pada lipstik dalam negeri dan luar negeri [6]. Pemilihan warna lipstik berdasarkan pada penelitian yang telah dilakukan oleh Ziarati et al (2012) [7] bahwa kadar timbal tertinggi terdapat pada lipstik warna merah muda $( \pm 40 \mu \mathrm{g} / \mathrm{g})$ dan kadar kadmium tertinggi terdapat pada lipstik warna coklat $( \pm 1,2$ $\mu \mathrm{g} / \mathrm{g})$.

Berdasarkan uraian diatas penulis menarik ingin melakukan penelitian apakah pada lipstik yang beredar di Pasar Brayan Medan Timur bebas dari logam berat Cadmium (Cd) dan Plumbum $(\mathrm{Pb})$ dengan menggunakan Spektrofotometri Serapan Atom (SSA).

\section{BAHAN DAN METODE}

\section{Bahan}

Larutan standar ICP multi-elemen standard solution IV, HNO3 (p), HNO3 5\%, Aquabidest, KI (Kalium lodida) dan $\mathrm{NaOH}$ (Natrium Hidroksida)

\section{Metode}

Metode penelitian ini merupakan penelitian yang bersifat eksperiment laboratorium (Laboratory Experiment) dengan melakukan pemeriksaan kadar logam berat Cadmium (Cd) dan Plumbum $(\mathrm{Pb})$ pada lipstik yang beredar di Pasar Brayan Medan Timur.

\section{Prosedur Penelitian}

Cara Operasi Alat Spektrofotometri Serapan Atom (SSA) - 240 FS

1. Dibuka gas asitilen (II PSI) dan $\mathrm{O}_{2}(50 \mathrm{PSI})$.

2. Dihidupkan blover (penghisap).

3. Dihidupkan PC beserta perangkatnya.

4. Dihidupkan SSA dengan menekan tombol ON.

5. Pilih program yang dianalisa lalu klik start kemudian tekan tombol pengapian.
6. Dimasukkan selang penghisap ketabung blanko, tabung standart dan tabung sampel.

7. Hasil akan terbaca pada dan ditampilkan pada layar PC.

8. Setelah selesai pemeriksaan burner akan mati secara otomatic.

9. Ditutup gas asitelen dan gas oksigen.

10. Dikeluar dari program SSA pada PC dan matikan alat dengan menekan Tombol Off.

\section{Kalibrasi alat Spektrofotometri Serapan Atom (SSA) - 240 FS}

1. Dinyalakan SSA.

2. Aktifkan Software Spectr AA.

3. Diklik Button Worksheet.

4. Diklik open lalu pilih worksheet yang akan digunakan.

5. Diklik Ok, sehingga muncul worksheet yang dinginkan.

6. Pada menu Develop diklik button edit Sequence Parameters.

7. Pada kolom start With, diklik Calibration dan ubah menjadi Reslope.

8. Diklik Ok.

\section{Analisa Kualitatif}

1. Dimasukkan $5 \mathrm{ml}$ sampel kedalam tabung reaksi, tambahkan $1 \mathrm{ml} \mathrm{NaOH}$ lalu homogenkan, amati apa yang terjadi bila terdapat endapan putih berarti sampel mengandung Cadmium (Cd).

2. Dimasukkan $5 \mathrm{ml}$ sampel kedalam tabung reaksi, tambahkan $1 \mathrm{ml} \mathrm{KI}$, lalu homogenkan, amati apa yang terjadi bila terdapat endapan kuning berarti sampel mengandung Plumbum (Pb).

\section{Analisa Kuantitatif}

Analisa kuantitatif dilakukan dengan menggunakan alat Spektrofotometri Serapan Atom (SSA).

\section{Cara Pembuatan Larutan Standart Cadmium (Cd)}

Larutan ICP multi-elemen standard solution IV $1000 \mathrm{mg} / \mathrm{L}$ dipipet $10 \mathrm{ml}$ dimasukkan labu ukur $100 \mathrm{ml}$, lalu tambahkan aquabides sampai tanda batas labu ukur. Diperoleh larutan dengan konsentrasi $100 \mathrm{mg} / \mathrm{L}$. Larutan konsentrasi 100 ppm dipipet $10 \mathrm{ml}$ dimasukkan dalam labu ukur $100 \mathrm{ml}$, lalu ditambahkan aquabides sampai tanda batas labu ukur. Diperoleh larutan dengan 
konsentrasi $10 \mathrm{mg} / \mathrm{L}$, kemudian diencerkan kembali menjadi 0,3 mg/L; 0,6 mg/L; 0,9 mg/L; $1,2 \mathrm{mg} / \mathrm{L}$ dalam labu ukur $100 \mathrm{ml}$. Larutan standar yang telah dibuat masing-masing diukur serapannya dengan SSA Pada panjang gelombang 228,8 $\mathrm{nm}$, dan hasilnya diplot menjadi kurva kalibrasi.

\section{Cara Pembuatan Larutan Standart Plumbum (Pb)}

Larutan ICP multi-elemen standard solution IV $1000 \mathrm{p} \mathrm{mg/L} \mathrm{dipipet} 10 \mathrm{ml}$ dimasukkan labu ukur $100 \mathrm{ml}$, lalu tambahkan aquabides sampai tanda batas labu ukur. Diperoleh larutan dengan konsentrasi $100 \mathrm{mg} / \mathrm{L}$. Larutan konsentrasi 100 $\mathrm{mg} / \mathrm{L}$ diencerkan menjadi 0,5 mg/L; 1,0 mg/L; 2,0 dan $4,0 \mathrm{mg} / \mathrm{L}$ dalam labu ukur $100 \mathrm{ml}$. Larutan standar yang telah dibuat masing-masing diukur serapannya dengan SSA Pada panjang gelombang $217,0 \mathrm{~nm}$, dan hasilnya diplot menjadi kurva kalibrasi.

\section{Preparasi Sampel}

Preparasi sampel dengan menggunakan metode dekstrusi kering yaitu sampel ditimbang \pm 1,00 gram, lalu dimasukkan kedalam cawan porselen $50 \mathrm{ml}$ kemudian dilakukan pengabuan dalam tanur dengan suhu $600^{\circ} \mathrm{C}$ selama 3 jam. Larutkan abu yang berwarna putih dengan $\mathrm{HNO}_{3}$ (p) sebanyak $5 \mathrm{ml}$ sambil dipanaskan diatas penangas listrik pada suhu $\pm 100^{\circ} \mathrm{C}$ hingga kering, lalu ditambahkan $\mathrm{HNO}_{3} 5 \%$ sebanyak 5 $\mathrm{ml}$ sambil dilakukan pemanasan pada suhu suhu $\pm 100^{\circ} \mathrm{C}$. Proses dekstrusi dihentikan sampai larutan jernih, yang menandakan bahwa proses dekstrusi telah sempurna setelah proses dekstrusi selesai, larutan didiamkan sampai dingin, lalu larutan dimasukkan kedalam labu ukur $50 \mathrm{ml}$ dan tambahkan aquabides sampai tanda batas labu ukur, kemudian larutan dihomogenkan. Lalu saring dengan menggunakan kertas saring Whatman 42 dan dimasukkan kedalam labu ukur $50 \mathrm{ml}$.

\section{Penentuan Cadmium (Cd) dalam Sampel}

Untuk menentukan kadar Cadmium pada lipstik mula-mula dilakukan pengukuran larutan standar yang telah dipersiapkan terlebih dahulu hingga diperoleh kurva kalibrasi dari larutan standar 0,0; menjadi $0,3 \mathrm{mg} / \mathrm{L} ; 0,6 \mathrm{mg} / \mathrm{L}$; $0,9 \mathrm{mg} / \mathrm{L} ; 1,2 \mathrm{mg} / \mathrm{L}$. Setelah itu dilakukan pengukuran serapan sampel. Pengukuran dilakukan dengan menggunakan SSA dengan panjang gelombang $228,8 \mathrm{~nm}$.

\section{Penentuan Plumbum $(\mathbf{P b})$ dalam Sampel}

Untuk menentukan kadar Plumbum pada lipstik mula-mula dilakukan pengukuran larutan standar yang telah dipersiapkan terlebih dahulu hingga diperoleh kurva kalibrasi dari larutan standar 0,$0 ; 0,5 \mathrm{mg} / \mathrm{L} ; 1,0 \mathrm{mg} / \mathrm{L} ; 2,0 \mathrm{mg} / \mathrm{L}$ dan $4,0 \mathrm{mg} / \mathrm{L}$. Setelah itu dilakukan pengukuran serapan sampel. Pengukuran dilakukan dengan menggunakan SSA dengan panjang gelombang $217,0 \mathrm{~nm}$.

\section{Perhitungan (BPOM RI, 2011)}

Hitung kadar $\mathrm{Cd}$ dan $\mathrm{Pb}$ dengan persamaan garis regresi kurva kalibrasi dengan menggunakan rumus:

$$
\frac{C(\mu g / m l)}{B(g)} x \mathrm{~F}(\mathrm{~mL})
$$

Dimana:

C $=$ Konsentrasi Cadmium atau Plumbum dalam sampel yang dihitung dari kurva kalibrasi dalam $\mu \mathrm{g} / \mathrm{ml}$.

$\mathrm{F}=$ Volume larutan uji dalam $\mathrm{mL}$.

$\mathrm{B}=$ Bobot sampel larutan dalam gram.

\section{Persyaratan Cemaran Logam Berat Cadmium dan Plumbum}

Menurut peraturan kepala BPOM RI Persyaratan cemaran logam berat Cadmium dan Plumbum Nomor HK.03.1.23.07.11.6662 adalah $(C d<5 \mathrm{mg} / \mathrm{L}$ dan $\mathrm{Pb}<20 \mathrm{mg} / \mathrm{L})$.

\section{HASIL DAN PEMBAHASAN}

Hasil penelitian Pemeriksaan Logam Berat Cadmium ( $C d$ ) dan Plumbum $(\mathrm{Pb})$ pada lipstik yang beredar di Pasar Brayan Medan Timur dengan metode random sampling sebanyak 5 sampel lipstik yang diambil dari Pasar Brayan Medan Timur, dilakukan pemeriksaan di Unit Pelayanan Teknis (UPT) Laboratorium Kesehatan Daerah Dinas Kesehatan Provinsi Sumatera Utara maka diperoleh hasil pada tabel berikut: 


\section{Tabel 1. Hasil Analisa Kualitatif dan Kuantitatif Logam Berat $C d$ dan Pb Pada Lipsti Yang Beredar di Pasar Brayan Medan Timur.}

\begin{tabular}{|l|l|l|l|c|c|c|c|c|}
\hline \multirow{2}{*}{ No } & \multirow{2}{*}{ Logam Berat } & \multirow{2}{*}{ Standar Baku } & \multirow{2}{*}{ Metode } & \multicolumn{4}{|c|}{ Kadar Logam Berat Pada Sampel (mg/L) } \\
\cline { 4 - 9 } & & & $\mathbf{1}$ & $\mathbf{2}$ & $\mathbf{3}$ & $\mathbf{4}$ & $\mathbf{5}$ \\
\hline \multirow{2}{*}{1.} & \multirow{2}{*}{ Cadmium $(\mathrm{Cd})$} & \multirow{2}{*}{$<\mathrm{mg} / \mathrm{L}$} & Kualitatif & $(-)$ & $(+)$ & $(-)$ & $(+)$ & $(-)$ \\
\cline { 4 - 9 } & & & Kuantitatif & 0,190 & 5,000 & 0,095 & 4,950 & 0,210 \\
\hline \multirow{2}{*}{2.} & \multirow{2}{*}{ Plumbum $(\mathrm{Pb})$} & \multirow{2}{*}{$20 \mathrm{mg} / \mathrm{L}$} & Kualitatif & $(+)$ & $(-)$ & $(+)$ & $(+)$ & $(+)$ \\
\cline { 4 - 9 } & & Kuantitatif & 0,915 & 0,180 & 0,295 & 6,960 & 1,515 \\
\hline
\end{tabular}

Pada Tabel 1 diatas menunjukkan hasil pemeriksaan kualitatif dan kuantitatif logam berat Cd pada sampel satu (1) memperoleh hasil negatif dengan nilai kadar $0.190 \mathrm{mg} / \mathrm{L}$, pada sampel dua (2) memperoleh hasil positif dengan nilai kadar $5,000 \mathrm{mg} / \mathrm{L}$, sedangkan sampel tiga (3) memperoleh hasil sebesar $0,095 \mathrm{mg} / \mathrm{L}$ dengan hasil negatif dan pada sampel empat (4) memperoleh hasil positif dengan nilai kadar $4,950 \mathrm{mg} / \mathrm{L}$ dan pada sampel lima (5) memperoleh hasil negatif dengan nilai kadar sebesar 0,210 $\mathrm{mg} / \mathrm{L}$. Dan pada logam berat $P b$ pada sampel satu (1) memperoleh hasil positif dengan nilai kadar $0,915 \mathrm{mg} / \mathrm{L}$ dan sampel dua (2) memperoleh hasil negatif dengan nilai kadar

$0,180 \mathrm{mg} / \mathrm{L}$ sedangkan pada sampel tiga (3) memperoleh hasil sebesar $0,295 \mathrm{mg} / \mathrm{L}$ dengan hasil positif dan pada sampel empat (4) memperoleh hasil positif dengan nilai kadar $6,960 \mathrm{mg} / \mathrm{L}$ dan sampel lima memperoleh hasil positif dengan nilai kadar $1,515 \mathrm{mg} / \mathrm{L}$.

\section{Pembahasan}

Lipstik yang digunakan harus aman dan tidak mengandung bahan yang berbahaya yang melebihi batas yang ditetapkan karena dapat ikut masuk melalui makanan dan minuman yang dikonsumsi [3].

Berdasarkan hasil penelitian dari lima sampel diperoleh tiga sampel negatif pada logam berat Cd yakni : pada sampel satu diperoleh $(0,190$ $\mathrm{mg} / \mathrm{L})$, tiga $(0,095 \mathrm{mg} / \mathrm{L})$ dan lima $(0,210 \mathrm{mg} / \mathrm{L})$ dan pada logam $C d$ yang memperoleh hasil positif ada dua sampel yakni: pada sampel dua dengan nilai $(5,000 \mathrm{mg} / \mathrm{L})$ dan sampel empat memperoleh hasil $(4,950 \mathrm{mg} / \mathrm{L})$. Sedangkan pada sampel logam berat $P b$ diperoleh empat sampel dengan hasil positif yakni sampel satu $(0,915 \mathrm{mg} / \mathrm{L})$, sampel tiga $(0,295 \mathrm{mg} / \mathrm{L})$ sedangkan sampel empat $(6,960 \mathrm{mg} / \mathrm{L})$ dan pada sampel lima $(1,515 \mathrm{mg} / \mathrm{L})$ sedangkan pada hasil sampel negatif hanya pada sampel dua $(0,180 \mathrm{mg} / \mathrm{L})$.

Standar yang digunakan dalam bahan kosmetik menurut peraturan BPOM RI Persyaratan cemaran logam berat Cadmium $(\mathrm{Cd})$ dan Plumbum (Pb) Nomor HK.03.1.23.07.11.6662 tahun 2011 adalah Cadmium $(C d)<5 \mathrm{mg} / \mathrm{L}$ dan Plumbum $(P b)<20$ $\mathrm{mg} / \mathrm{L}$. Kandungan logam berat $C d$ pada kelima sampel diperoleh tiga sampel dibawah nilai standar baku $(0,190 \mathrm{mg} / \mathrm{L}, 0,095 \mathrm{mg} / \mathrm{L}$ dan 0,210 $\mathrm{mg} / \mathrm{L}$ ) dan diikuti dua sampel yang mendekati standar baku yaitu : sampel dua $(5,000 \mathrm{mg} / \mathrm{L})$ dan pada sampel empat $(4,950 \mathrm{mg} / \mathrm{L})$. Hasil kelima sampel menunjukkan bahwa kandungan logam berat $C d$ pada sampel lipstik cenderung di bawah standar baku ( $<5 \mathrm{mg} / \mathrm{L})$, masih dalam katagori aman. Keracunan kronis yang disebabkan oleh logam berat Cadmium (Cd) dapat merusak sistem tubuh yakni pada ginjal, paru-paru, sistem sirkulasi darah dan jantung. Disamping itu keracunan kronis tersebut juga merusak kelenjar reproduksi, sistem penciuman dan bahkan dapat mengakibatkan kerapuhan pada tulang [8].

Dan kandungan logam berat $P b$ pada kelima sampel diperoleh lima sampel dibawah nilai standar baku yakni nilai sebesar $(0,915$ $\mathrm{mg} / \mathrm{L}, 0,180 \mathrm{mg} / \mathrm{L}, 0,295 \mathrm{mg} / \mathrm{L}, 1,515 \mathrm{mg} / \mathrm{L}$ dan $6,960 \mathrm{mg} / \mathrm{L}$ ) yakni pada kelima sampel masih dalam katagori aman. Logam berat Plumbum (Pb) dapat masuk dalam tubuh dengan jangka waktu yang lama akan menyebabkan gangguan kesehatan dalam tubuh. Senyawa Plumbum (Pb) yang masuk dalam tubuh dapat mempengaruhi metabolisme tubuh. Efek toksi Plumbum (Pb) dapat menghambat pembentukan $\mathrm{Hb}$, kerusakan sistem saraf, sistem reproduksi, jantung dan ginjal. Pada wanita hamil Plumbum (Pb) dapat melewati plasenta dan kemudian akan ikut masuk dalam sistem peredaran darah janin dan 
selanjutnya setelah bayi lahir, Plumbum (Pb) akan keluar bersama air susu ibu [4].

\section{KESIMPULAN}

Berdasarkan penelitian yang telah dilakukan dapat ditarik kesimpulan sebagai berikut:

1. Setelah dilakukan analisa kualitatif pada penelitian ini maka hasil yang didapat dari lima sampel yang mengandung logam berat Cadmium: dua sampel positif (sampel dua dan empat) dan tiga sampel negatif (sampel satu,tiga dan lima) sedangkan pada logam berat Plumbum: satu sampel negatif (sampel dua) dan sampel positif ada empat (sampel satu, tiga, empat dan lima).

2. Setelah dilakukan analisa kuantitatif secara Spektrofotometri Serapan Atom diperoleh kadar logam berat Cadmium (Cd): 0,190 $\mathrm{mg} / \mathrm{L}, 5,000 \mathrm{mg} / \mathrm{L}, 0,095 \mathrm{mg} / \mathrm{L}, 4,950 \mathrm{mg} / \mathrm{L}$ dan $0,210 \mathrm{mg} / \mathrm{L}$ dan kadar logam berat Plumbum $(P b): 0,915 \mathrm{mg} / \mathrm{L}, 0,180 \mathrm{mg} / \mathrm{L}$, $0,295 \mathrm{mg} / \mathrm{L}, 6,960 \mathrm{mg} / \mathrm{L}$ dan $1,515 \mathrm{mg} / \mathrm{L}$. Hasil dari keseluruhan sampel yang mengandung logam berat Cadmium (Cd) dan Plumbum $(\mathrm{Pb})$ dibawah standar baku.

\section{UCAPAN TERIMA KASIH}

Penulis mengucapkan terima kasih kepada Ketua Yayasan RSU Dr Rusdi Medan atas dukungannya dalam penelitian ini.

\section{REFERENSI}

[1] Muliyawan, D and Suriana, N. 2013. A-Z Tentang Kosmetik. Penerbit PT Elex Media Komputindo. Jakarta.

[2] Depkes RI, 1985. Formularium Kosmetika Indonesia. Direktorat Jendral Pengawasan Obat dan Makanan. Jakarta.

[3] Yatimah, D, Y. 2014. Analisis Cemaran Logam Berat Kadmium Pada Beberapa Merek Lipstik Yang Beredar Di Daerah Ciputat Dengan Menggunakan Spektrofotometri Serapan Atom (SSA). Skripsi Sarjana Kedokteran dan IImu Kesehatan Program Studi Farmasi. Jakarta.

[4] Widowati, W., Sastiono, A. dan Jusuf, R.R. 2008. Efek Toksik Logam Pencegah dan Penanggulangan Pencemaran. Penerbit Andi, Yogyakarta.

[5] Harmawan, T. 2017. Analisa Kadar Logam Berat Merkuri $(\mathrm{Hg})$ Pada Krim Pemutih Yang Beredar Di Daerah Percut Sei Tuan Sampali Secara Spektrofotometri Serapan Atom (SSA). CIRCUIT J IIm Pendidik Tek Elektro;1(2):74-9.
[6] Supriyadi. 2008. Analisis Logam Kadmium, Timbal, dan Krom pada Lipstik Secara Spektrofotometri Serapan Atom. Jurnal Kimia dan Teknologi, 4: 299-305.

[7] Ziarati, P. I., 2012. Risk Assesment of Heavy Metal Contens (Lead and Cadmium) in Lipstiks in Iran. IJCEA: 3(6): 450-452.

[8] Palar, H. (2008). Pencemaran dan Toksikologi Logam Berat. PT. Rineka Cipta, Jakarta. 